\title{
High resolution mapping of restoration of fertility $(R f)$ by combining large population and high density genetic map in pigeonpea [Cajanus cajan (L.) Millsp]
}

\author{
Rachit K. Saxena ${ }^{1 *}\left(\mathbb{D}\right.$, Johiruddin Molla ${ }^{1,2}$, Pooja Yadav and Rajeev K. Varshney ${ }^{1 *}$ (D)
}

\begin{abstract}
Background: Restoration of fertility $(R f)$ is an important trait for pigeonpea hybrid breeding. Few coarse quantitative trait locus (QTL) studies conducted in the past identified QTLs with large confidence intervals on the genetic map and could not provide any information on possible genes responsible for $R f$ in pigeonpea. Therefore, a larger population comprising of $369 \mathrm{~F}_{2} \mathrm{~S}$ derived from ICPA $2039 \times \mathrm{ICPL} 87119$ was genotyped with high density Axiom Cajanus SNP Array with $56 \mathrm{~K}$ single nucleotide polymorphism (SNPs) for high resolution mapping of Rf.

Results: A genetic map with 4867 markers was developed and a total of four QTLs for Rf were identified. While one major effect QTL ( $q$ Rf8.1) was co-localized with the QTL identified in two previous studies and its size was refined from 1.2 Mb to $0.41 \mathrm{Mb}$. Further analysis of aRf8.1 QTL with genome sequence provided 20 genes including two genes namely flowering locus protein $T$ and 2-oxoglutarate/Fe (II)-dependent dioxygenases (2-ODDs) superfamily protein with known function in the restoration of fertility.

Conclusion: The qRf8.1 QTL and the potential candidate genes present in this QTL will be valuable for genomicsassisted breeding and identification of causal genes/nucleotides for the restoration of fertility in the hybrid breeding program of pigeonpea.
\end{abstract}

Keywords: Pigeonpea, Hybrids, Restoration of fertility, Genetic map, QTL, Candidate gene

\section{Background}

Success of the three-line hybrid breeding system i.e. cytoplasmic genetic male sterility system (CGMS) in any crop species depends on the stability of male sterility and extent/frequency of restoration of fertility $(R f)$. It is also important to note that $R f$ is crucial in influencing the yield of hybrid plants. Some studies in past indicated that $R f$ is affected by both minor and major effect quantitative traits loci (QTLs) in pigeonpea [Cajanus cajan

\footnotetext{
*Correspondence: r.saxena@cgiar.org; r.k.varshney@cgiar.org 1 International Crops Research Institute for the Semi-Arid Tropics (ICRISAT), Hyderabad 502324, India

Full list of author information is available at the end of the article
}

(L.) Millsp.] [1, 2]. High resolution mapping, fine mapping and subsequently cloning of these QTLs to identify the genes will be useful for pigeonpea improvement. The importance of high resolution mapping and fine mapping has been realized in a number of crop species for several disease resistance and agronomic traits [3-8]. Moreover, QTLs/ genes associated with $R f$ have been isolated in few crops and vegetable species including barley [9], maize [10] and Chinese cabbage [11].

In the case of pigeonpea, majority of QTL studies were based on relatively small population size and a few hundred molecular markers [1, 2]. As a result, QTLs identified in the previous studies were quite big with a

(c) The Author(s). 2020 Open Access This article is licensed under a Creative Commons Attribution 4.0 International License, which permits use, sharing, adaptation, distribution and reproduction in any medium or format, as long as you give appropriate credit to the original author(s) and the source, provide a link to the Creative Commons licence, and indicate if changes were made. The images or other third party material in this article are included in the article's Creative Commons licence, unless indicated otherwise in a credit line to the material. If material is not included in the article's Creative Commons licence and your intended use is not permitted by statutory regulation or exceeds the permitted use, you will need to obtain permission directly from the copyright holder. To view a copy of this licence, visit http://creativecommons.org/licenses/by/4.0/. The Creative Commons Public Domain Dedication waiver (http://creativecommons.org/publicdomain/zero/1.0/) applies to the data made available in this article, unless otherwise stated in a credit line to the data. 
confidence interval ranged from $7 \mathrm{cM}$ to $23 \mathrm{cM}[1,2]$. Such QTLs, though serve the purpose of genomics assisted breeding (GAB) if they explain higher phenotypic variation (PVE), can also bring linkage drag during their introgression in the elite varieties. Furthermore, high resolution mapping of such big QTLs can help identification of candidate genes with causal polymorphism with a trait to develop diagnostic markers and precise transfer of gene/small genomic region for the trait in the elite varieties. In general, the size of QTL and the extent of PVE of the QTLs mainly depend on: (i) size and the trait variation in the mapping population, and (ii) marker density on the genetic map. Limited or less number of individuals in a given segregating/ mapping population may lead to biases in QTL mapping studies. It may affect the mapping, PVE and accuracy of QTL. To overcome the limitation of population size in QTL mapping, a number of approaches have been proposed in several studies [1215]. One of these approaches is to include more individuals in a given population for high resolution mapping after a coarse QTL study [13].

Another key factor in determining the QTL size is the number of molecular markers mapped on to the genetic map used for QTL study. High-density genetic map can localize recombination events more precisely and would help in reducing the QTL size or identification of new QTLs that were not identified with sparse genetic map. Recent advances in next generation sequencing (NGS) and high-throughput genotyping have facilitated development of high density genetic maps in different crop species including pigeonpea [2]. Such high density genetic maps can be used for identification of QTLs in smaller window providing higher resolution of QTLs.

Considering the importance of above mentioned two points in QTL detection i.e. population size and high density genetic maps, high resolution mapping studies have been conducted in several crops like Brassica [5, 7]), cotton [5], chickpea [16] and rice [3, 4]. For instance, in the case of chickpea, high-density bin map was used to fine map the "QTL-hotspot" region. In fact, "QTL-hotspot" region was split into two sub regions and candidate genes for drought tolerance were identified in this study [16]. Similarly, in maize, high density genotyping and large recombinant inbred population were used for the identification of QTLs for plant architecture related traits [17]. Therefore, in the present study, we have performed high-throughput SNP genotyping using the Axiom Cajanus SNP Array with 56 K SNPs [18] on extended population of $369 \mathrm{~F}_{2} \mathrm{~s}$ derived from ICPA $2039 \times$ ICPL 87119 to construct a high-density genetic map and undertake high resolution mapping of QTL region associated with $R f$ in pigeonpea.

\section{Result}

\section{High density genetic map}

High-quality genotyping data were generated on $369 \mathrm{~F}_{2} \mathrm{~S}$ along with parental lines using $56 \mathrm{~K}$ Axiom Cajanus SNP Array. These $56 \mathrm{~K}$ SNPs were having their predefined positions on the pigeonpea genome and more details on this SNP Array could be seen in Saxena et al. [18]. In summary, high- quality data were obtained for a total of 56,512 SNPs. SNP genotyping data were further subjected to different filtering parameters such as missing data points, heterozygous and monomorphic SNPs. Finally, a set of 12,079 SNPs showed polymorphisms between the parents of the mapping population. The identified polymorphic SNPs were evaluated for expected Mendelian segregation ratios through Chi-square analyses. The SNPs with distorted segregation ratio were removed. As a consequence, 7711 SNPs were used for the construction of genetic map. The final genetic map was comprised of 4867 SNPs distributed on 11 CcLGs (Fig. 1 and Table 1). The genetic map encompassed $1580.68 \mathrm{cM}$, with 11 CcLGs ranging from $50 \mathrm{cM}$ (CcLG05) to 197.1 cM (CcLG08). The lowest and highest number of SNPs were mapped on CcLG05 (115 SNPs) and CcLG02 (719 SNPs), respectively. But the percentage of SNPs mapped from the total polymorphic SNPs was highest on CcLG04 (86.3\%) and lowest on CcLG11 (41.73\%). Whereas, lowest marker density was found on CcLG01 and CcLG05 (2.3 markers/cM), and highest marker density was on CcLG02 (3.91 markers/cM).

\section{Fine mapping of $R f$}

High density genotyping data generated in the present study together with previously generated phenotyping data [2] for $R f$ were used for the QTL analysis. Though we have used all $415 \mathrm{~F}_{2} \mathrm{~S}$ for DNA isolation but high quality genotyping data could be generated on $369 \mathrm{~F}_{2} \mathrm{~s}$ and parental lines. ICIM analysis provided a total of four QTLs for $R f$ distributed on 3 CcLGs (Table 2). Identified QTLs were designated as $q R f 7, q R f 8.1, q R f 8.2$, and $q R f 9$. The $q R f 7$ flanked by Affx-123,311,044 - Affx-123,323, 924 on CcLG07, qRf8.1 flanked by Affx-123,357,076 Affx-123,360,361, qRf8.2 flanked by Affx-123,318,646Affx-123,334,846 on CcLG08 and $q R f 9$ flanked by Affx123,344,569- Affx-123,309,157 on CcLG09. The identified QTLs with PVE equal to or higher than $10 \%$ were considered as major QTL and those showing less than < $10 \%$ considered as minor QTL. The PVE of the QTLs was in the range from $2.34 \%$ ( $q R f 7$ ) to $45.06 \%$ ( $q R f 8.1$ ). In terms of localization of QTLs on CcLGs, the CcLG08 contained one major QTL namely qRf8.1 (PVE 45.06\%) (Fig. 2) and one minor QTL, qRf8.2 (PVE 2.79\%). While the remaining two minor QTLs were located one each on CcLG07 ( $q R f 7$ with PVE 2.34\%) and on CcLG09 (qRf9 with PVE 5.78\%) (Table 2). 


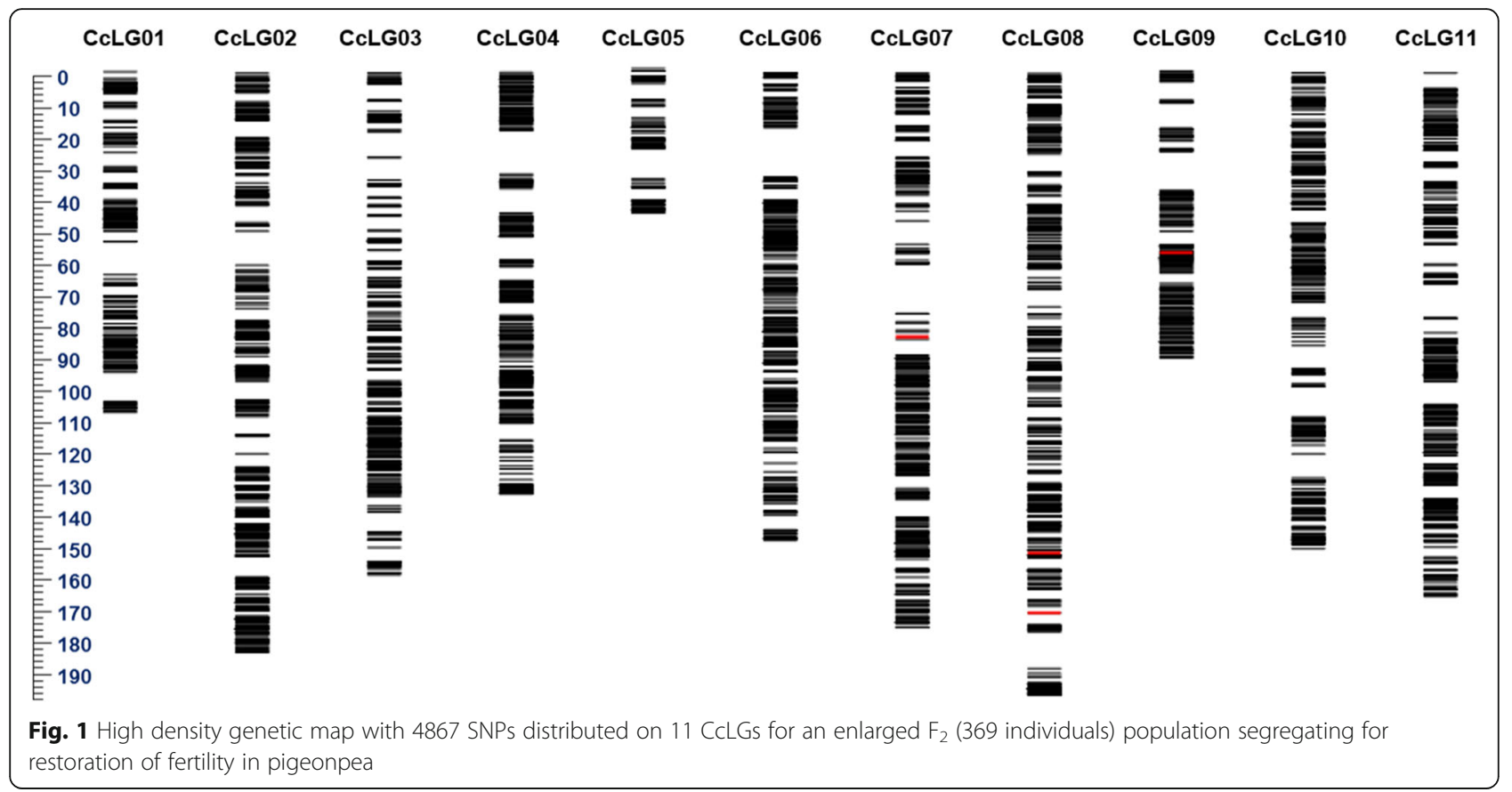

High resolution mapping and candidate genes for $R f$ In the past, only two studies have been conducted to locate the QTL regions associated with $R f$ in pigeonpea using different marker systems and mapping populations $[1,2]$. Therefore, to understand the advances achieved through high resolution mapping, results from this study were compared with the results obtained in previous studies. The first study was based on low density genetic maps derived from 78 to 140 simple sequence repeat (SSR) markers and four segregating populations with $188 \mathrm{~F}_{2}$ individuals each. This study identified a total of six major-effect QTLs across three populations. The
PVE of identified QTLs was in the range of 14.85 to 24.17\% [1]. In the second study, we used 306 SNPs based genetic map and $186 \mathrm{~F}_{2} \mathrm{~s}$ for $R f$ mapping [2]. This study provided one major QTL flanked by S8_7,664,779 to S8_ $6,474,381$ SNPs in $70.5 \mathrm{cM}-90.8 \mathrm{cM}$ confidence intervals on CcLG08 with PVE $28.5 \%$ and LOD 8.7 [2]. The results obtained through SSRs and SNPs from these two studies were also compared by mapping them on to the pigeonpea genome in this study. It was found that most of the major QTLs detected by Bohra et al. [1] were colocated with major QTL identified on CcLG08 by Saxena et al. [2]. The mapped positions of above mentioned

Table 1 Distribution of SNP markers on the genetic map for ICPA $2039 \times$ ICPL $87119\left(F_{2}\right)$ population

\begin{tabular}{|c|c|c|c|c|c|c|}
\hline CcLG & SNPs (polymorphic) & SNPs $(1: 2: 1)\left(P\right.$-value of $\left.<10^{-4}\right)$ & SNPs mapped & SNPs mapped (\%) & Mapping length (cM) & Number of markers per $\mathrm{cM}$ \\
\hline CcLG01 & 1106 & 466 & 256 & 54.93 & 111.3 & 2.3 \\
\hline CcLG02 & 1871 & 1231 & 719 & 58.4 & 184.06 & 3.91 \\
\hline CcLG03 & 1219 & 802 & 400 & 49.87 & 160.59 & 2.49 \\
\hline CcLG04 & 708 & 482 & 416 & 86.3 & 136.16 & 3.06 \\
\hline CcLG05 & 199 & 157 & 115 & 73.24 & 50 & 2.3 \\
\hline CcLG06 & 1157 & 731 & 546 & 74.69 & 150.18 & 3.64 \\
\hline CcLG07 & 1000 & 677 & 513 & 75.77 & 176.64 & 2.9 \\
\hline CcLG08 & 1056 & 734 & 631 & 85.96 & 197.1 & 3.2 \\
\hline CcLG09 & 617 & 426 & 281 & 65.96 & 94.87 & 2.96 \\
\hline CcLG10 & 1154 & 716 & 452 & 63.12 & 152.54 & 2.96 \\
\hline CcLG11 & 1992 & 1289 & 538 & 41.73 & 167.24 & 3.22 \\
\hline Total & 12,079 & 7711 & 4867 & 729.97 & 1580.68 & 3.07 \\
\hline Average & 1098.09 & 701 & 442.45 & 66.36 & 143.69 & 2.99 \\
\hline
\end{tabular}


Table 2 Summary of QTL mapping for $R f$ derived from $F_{2}$ (ICPA $2039 \times$ ICPL 87119)

\begin{tabular}{|c|c|c|c|c|c|c|c|c|}
\hline \multirow[t]{2}{*}{ QTL } & \multirow[t]{2}{*}{ CCLG } & \multirow{2}{*}{$\begin{array}{l}\text { Position } \\
\text { (cM) }\end{array}$} & \multicolumn{2}{|l|}{ Marker interval } & \multirow{2}{*}{$\begin{array}{l}\text { QTL size } \\
(\mathrm{Mb})\end{array}$} & \multirow[t]{2}{*}{ PVE\% } & \multirow{2}{*}{$\begin{array}{l}\text { LOD } \\
\text { value }\end{array}$} & \multirow{2}{*}{$\begin{array}{l}\text { Additive } \\
\text { effect }\end{array}$} \\
\hline & & & Genetic map & Genome & & & & \\
\hline qRf7 & CcLG07 & 84 & Affx-123,311,044 - Affx-123,323,924 & $3,491,625-5,770,779$ & 2.2 & 2.34 & 3.84 & -4.71 \\
\hline qRf8.1 & CcLG08 & 152 & Affx-123,357,076 - Affx-123,360,361 & $7,706,211-7,295,478$ & 0.41 & 45.06 & 51.58 & -30.63 \\
\hline qRf8.2 & CCLG08 & 171 & Affx-123,318,646 - Affx-123,334,846 & $4,209,765-3,895,976$ & 0.31 & 2.79 & 4.45 & -0.88 \\
\hline qRfg & CCLG09 & 60 & Affx-123,344,569 - Affx-123,309,157 & $8,976,251-8,933,062$ & 0.04 & 5.78 & 8.99 & -10.83 \\
\hline
\end{tabular}

QTLs were corresponding to 2.0 Mb [1] and 1.2 Mb [2] of pigeonpea genome.

In the present study using $56 \mathrm{~K}$ Cajanus SNP Array and $369 \mathrm{~F}_{2} \mathrm{~s}$, one major QTL ( $q R f 8.1$ ) flanked by Affx-123,357, 076 to Affx-123,360,361 on CcLG08 was identified. Phenotypic variance explained by $q R f 8.1$ was highest $(45.06 \%)$ across all the QTLs detected so far in different studies with LOD value 51.58. Moreover, QTLs positions on the reference genome across three studies were compared. It is important to note that major QTLs detected in past two studies either collocated or overlapping with the $q R f 8.1$. The present study could reduce the possible target genomic region for $R f$ from $2 \mathrm{Mb}$ [1] and $1.2 \mathrm{Mb}$ [2] to just $0.41 \mathrm{Mb}$ (Fig. 3, Table 3). In order to remove the software biasness while comparing the QTL sizes in present and previous SNPs based studies [2], earlier generated data with GBS based SNPs were also used for QTL mapping using ICIM with same parameters mentioned in the methods section.
The QTL region identified with the ICIM was almost similar in size $(1.27 \mathrm{Mb})$ as of identified through QTL cartographer in our previous study [2]. Further, target genomic region in $q R f 8.1$ was also searched for the presence of candidate genes. A total of 20 candidate genes were found in qRf8.1(Supplementary Table 1). Out of 20 candidate genes, two candidate genes namely flowering locus protein $\mathrm{T}$ and 2-oxoglutarate/Fe (II)-dependent dioxygenases (2-ODDs) superfamily protein have shown their role in restoration of fertility in different crop species [19, 20].

\section{Discussion}

In a number of crop species including pigeonpea large amount of genomic resources have become available [18, 21-25]. These genomic resources are being used in understanding and validating the basic biological, evolutionary concepts to downstream application in crop improvement and seed systems. In order to deploy

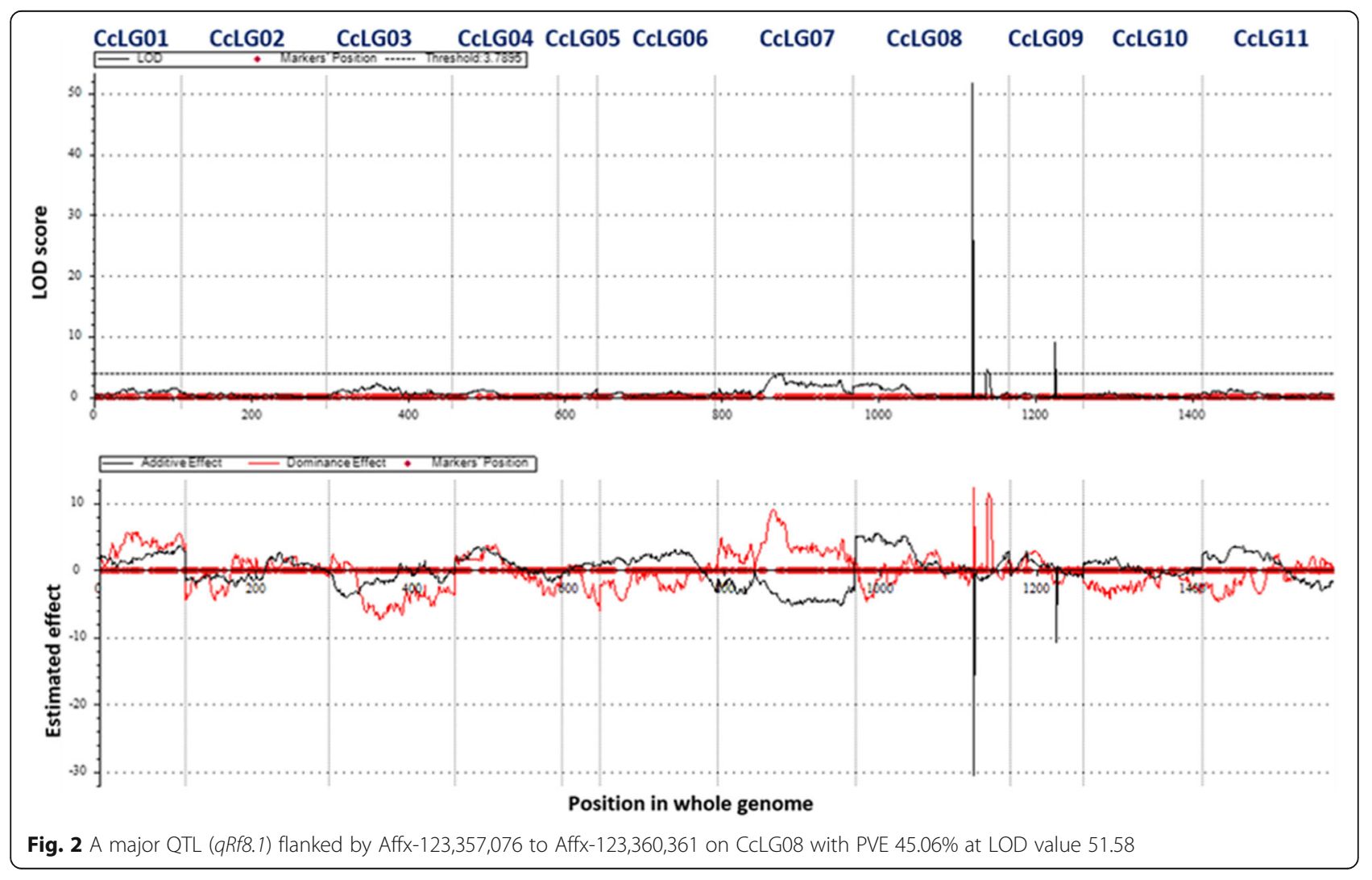




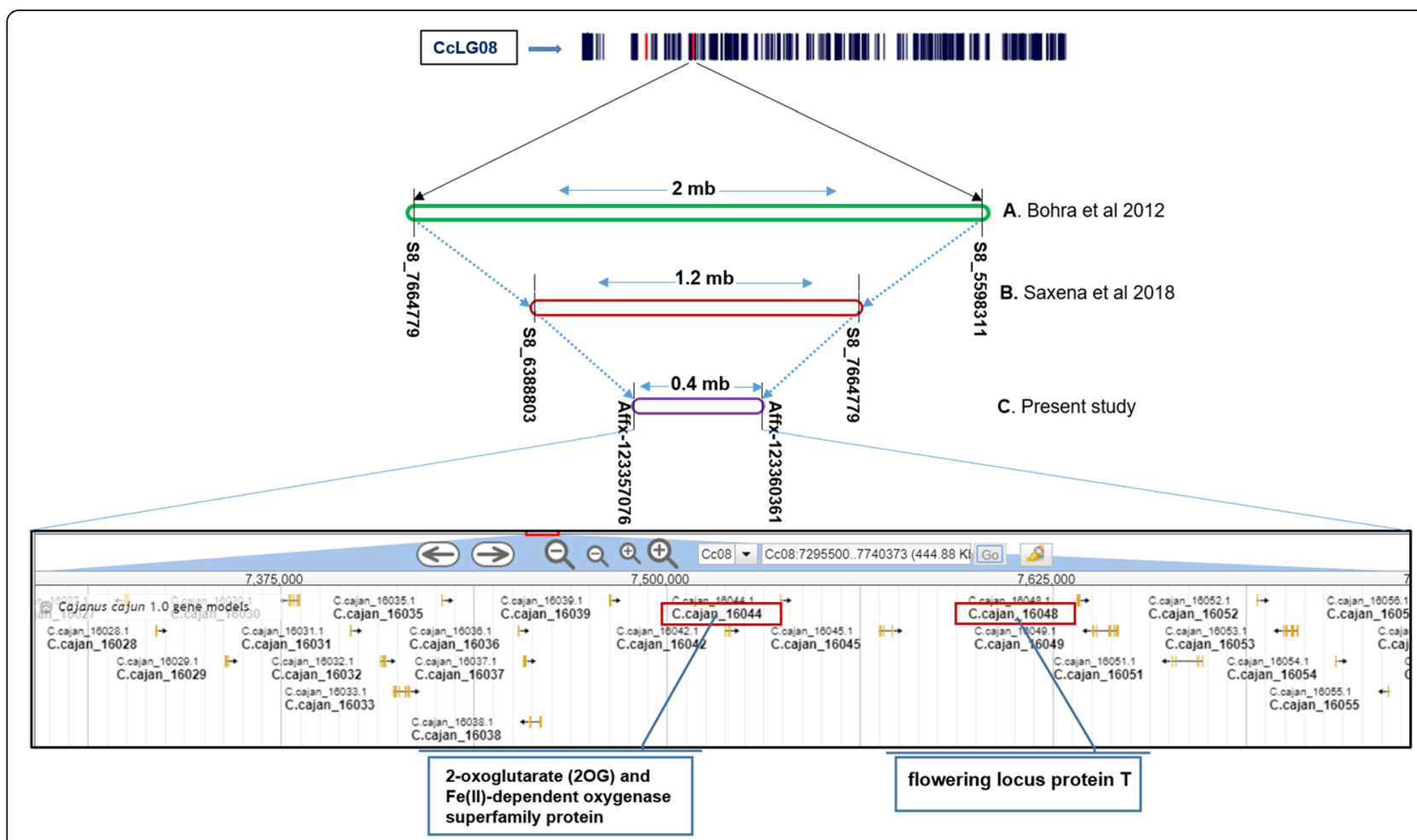

Fig. 3 Comparisons of the Rf associated QTLs identified in Bohra et al. [1] and Saxena et al. [2] with the present study and candidate genes detected

genomic resources for crop improvement, marker-trait associations need to be established and subsequently causal mutations or genes need to be identified. However, a large amount of genomic and genetic resources coupled with good strategies and commitment is required to go from association to causality in the genome for a given trait. Therefore, as a quick fix, marker- trait associations are established and used in GAB. Nevertheless, for precise selection of line for a trait in crop improvement programs, it will be good to identify causal mutation or QTLs in a minimum confidence interval. This will also help to avoid the issue of linkage drag during the transfer of QTLs in elite varieties.

High resolution mapping is an approach which can be used for shortening the large genomic segments identified in coarse QTL mapping [16]. Extending the population size and high-density genetic maps could improve the QTL mapping resolution [26, 27]. In the present study $369 \mathrm{~F}_{2}$ s and their genotyping with $56 \mathrm{~K}$ SNPs array as well as phenotyping data were used. This population has more than double individuals as compared to previously used population in coarse $R f$ QTL studies in pigeonpea [2]. Moreover, the genetic map developed in this study has around 16 to 62 fold higher markers density as compared to previous genetic maps used for $R f$ QTL studies in pigeonpea $[1,2]$. Furthermore, the major QTL "qRf8.1" has contributed almost half of the phenotypic variation $45.06 \%$ with LOD 51.6. Enhanced confidence level in terms of LOD and PVE values in the present study may be due to our high resolution mapping approach where large population has been used. Similar observations were made in maize, murine where LOD value considerably increased with the size of mapping population $[28,29]$.

All the $R f$ associated QTLs detected in this study including minor and major had significant additive effects for the trait. As expected, the alleles for increasing traits value were from ICPL 87119 for $q R f 7, q R f 8.1, q R f 8.2$ and

Table 3 Mapping and QTL comparison of present study with previous studies

\begin{tabular}{llllllll}
\hline $\begin{array}{l}\text { Population } \\
\text { size }\end{array}$ & $\begin{array}{l}\text { Mapped } \\
\text { markers }\end{array}$ & \multicolumn{2}{l}{ Average inter marker distance } & LOD & PVE \% & References \\
\cline { 3 - 6 } & Genetic map (cM) & Genome position & QTL size (Mb) & & \\
\hline 188 & $78-140$ SSRs & $7.3-3.1$ & $5,598,311$ to $7,664,779$ & 2 & 8.9 & $13.98-24.17$ & Bohra et al. 2012 [1] \\
186 & 306 SNPs & 3.2 & $6,474,381$ to $7,664,779$ & 1.2 & 8.7 & 28.5 & Saxena et al. 2018 [2] \\
369 & 4867 SNPs & 0.3 & $7,295,478$ to $7,706,211$ & 0.41 & 51.58 & 45.06 & Present study \\
\hline
\end{tabular}


qRf9 (Table 2). These mono parental additive effects suggest that the selection of ICPL 87119 as restorer parent was very appropriate and this line has a great potential to be used as one of the best restorers in pigeonpea hybrid breeding program. The high resolution mapping of $R f$ in the present study has also provided 20 potential candidate genes within major QTL-region (Supplementary Table 1). Among them two genes- flowering locus protein $\mathrm{T}$ (FT) and 2-oxoglutarate/Fe (II)-dependent dioxygenases (2-ODDs) superfamily protein play an important role in fertility $[19,20]$. The FT belongs to the FT-like family, which includes at least six close FT-like genes (FT1 to FT6) in wheat [30-32]. Recently it has been reported that FT1 and FT2 play an important role in spike development and fertility [20]. The other protein 2-oxoglutarate/Fe (II)-dependent dioxygenases (2ODDs) superfamily protein plays an important role on auxin concentration. This protein converts IAA into inactive oxIAA that in turn controls auxin concentration and homeostasis which is essential for reproductive development, including anther dehiscence, pollen fertility in rice and barley.

\section{Conclusion}

In summary, the present study has used high resolution mapping by combining a large population and high density markers. Besides the increased resolution of genetic map and QTL region, several genes with known functions have been identified. With the enhanced confidence and multiple validations across different mapping populations used in past and present studies, flanking markers of " $q R f 8.1$ " can be used in GAB. Furthermore, potential candidate genes in this QTL region will be helpful in identification, cloning and functional validation of causal mutation or gene/s responsible for $R f$ in pigeonpea.

\section{Methods}

\section{Mapping population and DNA isolation}

For mapping $R f$, one $\mathrm{F}_{2}$ mapping population was developed from CMS line ICPA 2039 and its known fertility restorer ICPL 87119 [2]. The seeds of crossing parental lines were obtained from ICRISAT pigeonpea improvement program. However only a subset of this population i.e. $186 \mathrm{~F}_{2} \mathrm{~s}$ was used in coarse QTL mapping for $R f$ [2]. In the present study, however, all $415 \mathrm{~F}_{2} \mathrm{~S}$ from the above mentioned population were used.

Young leaves from individual plants and parental lines were used to isolate genomic DNA using NucleoSpin plant extraction kit (MACHEREY-NAGEL, USA). The quality and quantity of DNA were checked on $0.8 \%$ agarose gel and NanoDrop ${ }^{\mathrm{Tm}} 8000$ Spectrophotometer (Thermo Scientific, US), respectively.

\section{Genotyping and construction of genetic map}

DNAs from $415 \mathrm{~F}_{2} \mathrm{~s}$ were used for high density genotyping through $56 \mathrm{~K}$ Axiom Cajanus SNP Array as described in Saxena et al. [18]. However, high quality genotyping data were used for only $369 \mathrm{~F}_{2} \mathrm{~s}$ for construction of the genetic map. In this regard, called SNPs with respect to the two parents were first tested against the expected Mendelian segregation ratios (1:2:1). SNPs following expected segregation ratio at a $P$-value of $<10^{-4}$ were retained and used for the construction of genetic map.

Genotyping data were assembled for all segregating markers on all $F_{2}$ individuals and linkage analysis was performed using regression mapping algorithm by ICIM software v4.1 [33]. Map calculations were performed with default parameters and in addition of a new locus may influence the optimum map order; hence, a "Ripple" was used. The Kosambi mapping function was used to convert recombination fraction into map units [34]. The visualization of genetic map was done using the software ICIM software v4.1 and MapChart 2.32 [35].

\section{QTL analysis and candidate genes}

QTL mapping for $R f$ was done by combining phenotyping data [2] together with SNP data generated in the present study. ICIM-ADD method with default parameters were used to detect QTL using ICIM software v4.1. The threshold of the LOD score for declaring the presence of a significant QTL was determined by the permutation test with 1000 repetitions at $P<0.05$. The nomenclature of QTLs was given as described in Yadav et al. [36]. Where QTLs include " $q$ " for quantitative trait followed by trait code (" $R f$ " for restoration of fertility) with Cajanus cajan linkage group (CcLG) number and chronological order of QTL for that trait on the CcLG separated by a dot. Further, candidate genes present within the major QTL region were retrieve from Cajanus cajan 1.0 gene model using JBrowse of legume information system (LIS). The function of these genes were predicted from gene search tool of LIS.

\section{Supplementary information}

Supplementary information accompanies this paper at https://doi.org/10. 1186/s12864-020-06859-6.

Additional file 1: Table 1. Potential candidate genes identified in major QTL region.

\section{Abbreviations}

CcLG: Cajanus cajan linkage group; CM: Centimorgan; DNA: Deoxyribonucleic acid; ICIM: Inclusive composite interval mapping; LOD: Logarithm of the odds; PVE: Phenotypic variance explained; QTL: Quantitative trait loci; SNP: Single nucleotide polymorphism 


\section{Acknowledgements}

This work has been undertaken as part of the CGIAR Research Program on Grain Legumes and Dryland Cereals (GLDC). ICRISAT is a member of CGIAR Consortium. Authors would also like to thank Mr. Suryanarayana and Mr. Sudhakar for the technical help.

\section{Authors' contributions}

RKS and RKV conceived the study. RKS, RKV, JM and PY designed the experiment and analysis. JM performed the data analyses with RKS and PY. RKS, JM, PY and RKV wrote the manuscript. All authors read and approved the final manuscript.

\section{Funding}

Authors are thankful to the Department of Agriculture Cooperation \& Farmers Welfare, Ministry of Agriculture \& Farmers Welfare, Government of India, Department of Biotechnology, Government of India, Tropical Legumes Project TLII from Bill and Melinda Gates Foundation for providing funding support in parts to the present study.

\section{Availability of data and materials}

All the data generated or analyzed during this study have been included in the present article as Tables and Figures.

\section{Ethics approval and consent to participate}

Not applicable.

\section{Consent for publication}

Not applicable.

\section{Competing interests}

The authors declare that they have no competing interests.

\section{Author details}

${ }^{1}$ International Crops Research Institute for the Semi-Arid Tropics (ICRISAT), Hyderabad 502324, India. ${ }^{2}$ Ghatal Rabindra Satabarsiki Mahavidyalay, Ghatal, Paschim Medinipur 721212, India.

\section{Received: 5 December 2019 Accepted: 22 June 2020}

\section{Published online: 03 July 2020}

\section{References}

1. Bohra A, Saxena RK, Gnanesh BN, Saxena KB, Byregowda M, Rathore A. An intra-specific consensus genetic map of pigeonpea [Cajanus cajan (L.) Millsp] derived from six mapping populations. Theor Appl Genet. 2012;125 1325-38.

2. Saxena RK, Patel K, Sameer Kumar CV, Tyagi K, Saxena KB, Varshney RK Molecular mapping and inheritance of restoration of fertility $(R f)$ in $A 4$ hybrid system in pigeonpea (Cajanus cajan (L.) Millsp.). Theor Appl Genet. 2018;131:1605-14.

3. Huang J, Hu J, Xu X, Li S, Yi P, Yang D, Ren F, Liu X, Zhu Y. Fine mapping of the nuclear fertility restorer gene for $\mathrm{HL}$ cytoplasmic male sterility in rice. Bot Bull Acad Sin. 2003:44:285-89.

4. Liu XQ, Xu X, Tan YP, Li SQ, Hu J, Huang JY, Yang DC, Li YS, Zhu YG. Inheritance and molecular mapping of two fertility-restoring loci for honglian gametophytic cytoplasmic male sterility in rice (Oryza sativa L.). Mol Gen Genomics. 2004;271:586-94.

5. Yi B, Chen $Y$, Lei $S, T u$ J, Fu T. Fine mapping of the recessive genic malesterile gene (Bnms1) in Brassica napus L. Theor Appl Genet. 2006;113:643-50.

6. He J, Ke L, Hong D, Xie Y, Wang G, Liu P, Yang G. Fine mapping of a recessive genic male sterility gene (Bnms3) in rapeseed (Brassica napus) with AFLP-and Arabidopsis-derived PCR markers. Theor Appl Genet. 2008;117:11-8.

7. Suresh PB, Srikanth B, Kishore VH, Rao IS, Vemireddy LR, Dharika N, Sundaram RM, Ramesha MS, Rao KS, Viraktamath BC, Neeraja CN. Fine mapping of Rf3 and Rf4 fertility restorer loci of WA-CMS of rice (Oryza sativa L.) and validation of the developed marker system for identification of restorer lines. Euphytica. 2012;187:421-35.

8. Liu L, Guo W, Zhu X, Zhang T. Inheritance and fine mapping of fertility restoration for cytoplasmic male sterility in Gossypium hirsutum L. Theor Appl Genet. 2003;106:461-9.
9. Rizzolatti C, Bury P, Tatara E, Pin PA, Rodde N, Bergès H, Budar F, Mireau H, Gielen JJ. Map-based cloning of the fertility restoration locus Rfm1 in cultivated barley (Hordeum vulgare). Euphytica. 2017;213:276.

10. Xie K, Wu S, Li Z, Zhou Y, Zhang D, Dong Z, An X, Zhu T, Zhang S, Liu S, Li J. Map-based cloning and characterization of Zea mays male sterility33 (ZmMs33) gene, encoding a glycerol-3-phosphate acyltransferase. Theor Appl Genet. 2018;131:1363-78.

11. Zhang H, Wu J, Dai Z, Qin M, Hao L, Ren Y, Li Q, Zhang L. Allelism analysis of BrRfp locus in different restorer lines and map-based cloning of a fertility restorer gene, BrRfp1, for pol CMS in Chinese cabbage (Brassica rapa L.). Theor Appl Genet. 2017;130:539-47.

12. Jansen RC. Controlling the type 1 and type 2 errors in mapping quantitative trait loci. Genetics. 1994:138:871-81.

13. Lander E, Kruglyak L. Genetic dissection of complex traits: guidelines for interpreting and reporting linkage results. Nat Genet. 1995:11:241-7.

14. Jansen RC. Quantitative trait loci in inbred lines. In: Balding DJ, Bishop M, Cannings $C$, editors. In 'handbook of statistical genetics'. New York: Wiley; 2001. p. 567-97.

15. Tucker DM, Griffey CA, Liu S, Brown-Guedira G, Marshall DS, Saghai Maroof MA. Confirmation of three quantitative trait loci conferring adult plant resistance to powdery mildew in two winter wheat populations. Euphytica. 2007;155:1-13

16. Kale SM, Jaganathan D, Ruperao P, Chen C, Punna R, Kudapa H, Thudi M, Roorkiwal M, Katta MA, Doddamani D, Garg V. Prioritization of candidate genes in "QTL-hotspot" region for drought tolerance in chickpea (Cicer arietinum L.). Sci Rep. 2015;5:15296.

17. Wang B, Zhu Y, Zhu J, Liu Z, Liu H, Dong X, Guo J, Li W, Chen J, Gao C, Zheng $X$. Identification and fine-mapping of a major maize leaf width qt in a re-sequenced large recombinant inbred lines population. Front Plant Sci. 2018;9:101.

18. Saxena RK, Rathore A, Bohra A, Yadav P, Das RR, Khan AW, Singh VK, Chitikineni A, Singh IP, Kumar CV, Saxena KB. Development and application of high-density axiom Cajanus SNP Array with 56K SNPs to understand the genome architecture of released cultivars and founder genotypes. Plant Genome. 2018;1:1-10.

19. Zhao Z, Zhang Y, Liu X, Zhang X, Liu S, Yu X, Ren Y, Zheng X, Zhou K, Jiang $L$, Guo $X$. A role for a dioxygenase in auxin metabolism and reproductive development in rice. Dev Cell. 2013;27:113-22.

20. Shaw LM, Lyu B, Turner R, Li C, Chen F, Han X, Fu D, Dubcovsky J. FLOWERING LOCUS T2 regulates spike development and fertility in temperate cereals. J Exp Bot. 2018;70:193-204.

21. Saxena RK, Varma Penmetsa R, Upadhyaya HD, Kumar AS, Carrasquilla-Garcia NO, Schlueter JA, Farmer AN, Whaley AM, Sarma BK, May GD, Cook DR. Large-scale development of cost-effective single-nucleotide polymorphism marker assays for genetic mapping in pigeonpea and comparative mapping in legumes. DNA Res. 2012;19:449-61.

22. Varshney RK, Kudapa H, Roorkiwal M, Thudi M, Pandey MK, Saxena RK. Advances in genetics and molecular breeding of three legume crops of semi-arid tropics using next-generation sequencing and high-throughput genotyping technologies. J Biosci. 2012;37:811-20.

23. Singh NK, Gupta DK, Jayaswal PK. The first draft of the pigeonpea genome sequence. J Plant Biochem Biotechnol. 2012;21:98-112.

24. Roorkiwal M, Sawargaonkar SL, Chitikineni A, Thudi M, Saxena RK, Upadhyaya HD, Vales MI, Riera-Lizarazu O, Varshney RK. Single nucleotide polymorphism genotyping for breeding and genetics applications in chickpea and pigeonpea using the BeadXpress platform. The plant genome. 2013;6:2.

25. Varshney RK, Saxena RK, Upadhyaya HD. Whole-genome resequencing of 292 pigeonpea accessions identifies genomic regions associated with domestication and agronomic traits. Nat Genet. 2017:49:1082-8.

26. Vales M, Schön C, Capettini F, Chen X, Corey A, Mather DE, Mundt C, Richardson K, Sandoval-Islas J, Utz H, Hayes PM. Effect of population size on the estimation of QTL: a test using resistance to barley stripe rust. Theor Appl Genet. 2005;111:1260-70.

27. Hung H-Y, Shannon LM, Tian F, Bradbury PJ, Chen C, Flint-Garcia SA, McMullen MD, Ware D, Buckler ES, Doebley JF, Holland JB. ZmCCT and the genetic basis of day-length adaptation underlying the post domestication spread of maize. Proc Natl Acad Sci U S A. 2012;109:1913-21.

28. Schön CC, Utz HF, Groh S, Truberg B, Openshaw S, Melchinger AE. Quantitative trait locus mapping based on resampling in a vast maize 
testcross experiment and its relevance to quantitative genetics for complex traits. Genetics. 2004;167:485-98.

29. Li X, Quigg RJ, Zhou J, Xu S, Masinde G, Mohan S, Baylink DJ. A critical evaluation of the effect of population size and phenotypic measurement on QTL detection and localization using a large F2 murine mapping population. Mol Gen Genomics. 2006;29:166-73.

30. Faure S, Higgins J, Turner A, Laurie DA. The flowering locus T-like gene family in barley (Hordeum vulgare). Genetics. 2007;176:599-609.

31. Lv B, Nitcher R, Han X, Wang S, Ni F, Li K, Pearce S, Wu J, Dubcovsky J, Fu D. Characterization of flowering locus T1 (FT1) gene in Brachypodium and wheat. PLoS One. 2014;9:e94171.

32. Halliwell J, Borrill P, Gordon A, Kowalczyk R, Pagano ML, Saccomanno B, Bentley AR, Uauy C, Cockram J. Systematic investigation of flowering locus T-like Poaceae gene families identifies the short-day expressed flowering pathway gene, TaFT3 in wheat (Triticum aestivum L.). Front Plant Sci. 2016;7: 857.

33. Lei M, Li H, Zhang L, Wang J. QTL IciMapping: integrated software for genetic linkage map construction and quantitative trait locus mapping in biparental populations. Crop J. 2015;3:269-83.

34. Kosambi DD. The estimation of map distances from recombination values. Ann Eugenics. 1943;12:172-5.

35. Voorrips RE. MapChart: software for the graphical presentation of linkage maps and QTLs. J Hered. 2002;93:77-8.

36. Yadav P, Saxena KB, Hingane A, Kumar CS, Kandalkar VS, Varshney RK, Saxena RK. An "axiom Cajanus SNP Array" based high density genetic map and QTL mapping for high-selfing flower and seed quality traits in pigeonpea. BMC Genomics. 2019;20:235.

\section{Publisher's Note}

Springer Nature remains neutral with regard to jurisdictional claims in published maps and institutional affiliations.

Ready to submit your research? Choose BMC and benefit from:

- fast, convenient online submission

- thorough peer review by experienced researchers in your field

- rapid publication on acceptance

- support for research data, including large and complex data types

- gold Open Access which fosters wider collaboration and increased citations

- maximum visibility for your research: over $100 \mathrm{M}$ website views per year

At BMC, research is always in progress.

Learn more biomedcentral.com/submissions 